\title{
Work engagement and psychological capital in the Italian public administration: A new resource-based intervention programme
}

\begin{tabular}{|c|c|}
\hline $\begin{array}{l}\text { Authors: } \\
\text { Arianna Costa } \\
\text { Francesco De } \\
\text { Andrea Cesch } \\
\text { Riccardo Sart } \\
\text { Anna M. Men } \\
\text { Annamaria Di }\end{array}$ & $\begin{array}{l}\text { ntini }{ }^{1} \text { (1) } \\
\text { Paola }^{1} \text { (1) } \\
1 \text { (1) } \\
\text { ri }^{1} \text { (1) } \\
\text { eghini }{ }^{1} \text { (1) } \\
\text { Fabio }^{2} \text { (1) }\end{array}$ \\
\hline \multicolumn{2}{|c|}{$\begin{array}{l}\text { Affiliations: } \\
{ }^{1} \text { Department of Human } \\
\text { Sciences, Verona University, } \\
\text { Italy }\end{array}$} \\
\hline \multicolumn{2}{|c|}{$\begin{array}{l}{ }^{2} \text { Department of Education } \\
\text { and Psychology Sciences, } \\
\text { University of Florence, Italy }\end{array}$} \\
\hline \multicolumn{2}{|c|}{$\begin{array}{l}\text { Corresponding author: } \\
\text { Arianna Costantini, } \\
\text { arianna.costantini@univr.it }\end{array}$} \\
\hline $\begin{array}{l}\text { Dates: } \\
\text { Received: } 01 \\
\text { Accepted: } 03 \\
\text { Published: } 16\end{array}$ & $\begin{array}{l}\text { Received: } 01 \text { Oct. } 2016 \\
\text { Accepted: } 03 \text { Apr. } 2017\end{array}$ \\
\hline \multicolumn{2}{|c|}{$\begin{array}{l}\text { How to cite this article: } \\
\text { Costantini, A., De Paola, F., } \\
\text { Ceschi, A., Sartori, R., } \\
\text { Meneghini, A.M., \& Di Fabio, } \\
\text { A., (2017). Work engagement } \\
\text { and psychological capital in } \\
\text { the Italian public } \\
\text { administration: A new } \\
\text { resource-based intervention } \\
\text { programme. SA Journal of } \\
\text { Industrial Psychology/SA } \\
\text { Tydskrif vir Bedryfsielkunde, } \\
\text { 43(0), a1413. https://doi.org/ } \\
\text { 10.4102/sajip.v43i0.1413 }\end{array}$} \\
\hline \multicolumn{2}{|c|}{$\begin{array}{l}\text { Copyright: } \\
\text { @ 2017. The Authors } \\
\text { Licensee: AOSIS. This } \\
\text { is licensed under the } \\
\text { Creative Commons } \\
\text { Attribution License. }\end{array}$} \\
\hline \multicolumn{2}{|l|}{ Read online: } \\
\hline 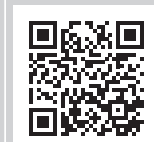 & $\begin{array}{l}\text { Scan this QR } \\
\text { code with your } \\
\text { smart phone or } \\
\text { mobile device } \\
\text { to read online. }\end{array}$ \\
\hline
\end{tabular}

Orientation: Organisations need energetic and dedicated employees to enhance the quality of their services and products continuously. According to the Conservation of Resources Theory, it is possible to increase work engagement of employees by improving their personal resources.

Research purpose: The main aim of this study was to examine the extent to which an improvement in psychological capital, as a personal resource, might enhance work engagement of employees in the public sector.

Motivation for the study: This study was developed to investigate how and to what extent interventions aiming at fostering higher work engagement through the enhancement of psychological capital were certainly effective.

Research design, approach and method: To improve psychological capital, a new resourcebased intervention programme (FAMILY intervention) was developed and applied, in which six dimensions - namely framing, attitudes, meaningfulness, identity, leading self and yoked together - were improved. A semi-experimental research design (pre-test and post-test) was used to conduct this study. Participants were 54 employees working in an Italian public health administration. In the pre-test and post-test stages, data were collected by using the psychological capital and work engagement scales.

Main findings: Results showed that there is a positive relationship between psychological capital and work engagement in the pre-test and post-test stages, considered separately. In addition, comparing pre-test and post-test results revealed that the intervention programme significantly improved both psychological capital and work engagement. This shows that an improvement in psychological capital is consistent with an increase in work engagement.

Conclusion: Together, these findings prove that psychological capital can be considered as a set of personal resources which lead to increased work engagement.

Contribution/value-add: This study bridged the gap found in the literature between the role of psychological capital in fostering higher work engagement and the extent to which interventions are effective among employees working in public administration.

\section{Introduction}

The perceived image of the public sector has been in decline since the 1960s, with public employees typically being stereotyped as lazy, inefficient and basically demotivated (Osborne \& Gaebler, 1992). The resultant negative connotations associated with cumbersomely led public agencies (Goodsell, 2003) have caused what Jacobson (2011) defines as a 'human capital crisis', with public service careers appealing to only a few. This stereotyped image of the lazy and idle employee, lacking motivation or a sense of responsibility, is even more evident in some European countries such as Italy (Pipan, 2000), where the organisational culture of public agencies has not really changed, despite recent efforts of the government to make a cultural change through public management reforms (Cristofoli, Nasi, Turrini, \& Valotti, 2011).

Moreover, as in many other countries, the Italian public administration is still suffering from some structural weaknesses that let an insidious form of bureaucratic inertia overstay at any level of the public institutions, delaying the implementation of innovative practices (Merlicco, 2008). However, because many academics and practitioners claim such an inertia in the reform implementation (Cristofoli et al., 2011), this has encouraged researchers to look for methods and interventions in order to make changes to the attitudes and perceptions of public sector employees and minimise this 
stereotypical image of public administration (Vigoda-Gadot \& Meiri, 2008). Among these efforts, work engagement was recognised as a central factor to enhance motivation and retention among public sector employees (Saks, 2006). Work engagement represents a positive, affective-motivational, work-related state of mind characterised by vigour, fulfilment, absorption and dedication while an employee is performing tasks at the workplace (Schaufeli, Salanova, Gonzalez-Roma \& Bakker, 2002).

\section{Research purpose and objectives}

Even though different studies have been conducted to identify methods for improving work engagement, our investigation shows that little is known about personal resources that could enhance work engagement in an occupational setting. In Italy, it is particularly important to look for interventions able to enhance work engagement while respecting organisational rules. Indeed, researchers are often not allowed to implement large interventions because of organisational policies and bureaucratic constraints (Merlicco, 2008). As such, in this study we will first focus on the impact of psychological capital on work engagement among Italian employees. Secondly, we will examine the impact of a new resource-based intervention programme, known as FAMILY intervention, on the enhancement of both psychological capital and work engagement in the public administration sector. To the best of our knowledge, there is no existing literature review of positive psychology interventions focusing on organisational outcomes (with reference to specific organisational settings such as public administration), other than well-being or mental illness (depression, anxiety, stress, etc.) (Meyers, van Woerkom \& Bakker, 2013). These reasons provide the impetus for and contribution of our study.

\section{Literature review}

\section{Work engagement: From definition to outcomes}

Work engagement is an emerging concept in occupational health psychology (Shimazu \& Schaufeli, 2008; Wirtz, Rigotti, Otto \& Loeb, 2016). Evidence shows that engaged employees have a sense of energetic and effective connection with their work activities, and they see themselves as capable of managing the demands of their job (Bakker \& Demerouti, 2008). Researchers believe that work engagement is a positive behaviour or mind-set at work that leads to positive workrelated outcomes (Seligman \& Csikszentmihalyi, 2000). As such, Schaufeli, Salanova, González-Romá and Bakker (2002) define it as a positive, fulfilling, work-related state of mind characterised by vigour, dedication and absorption. Based on the latter definition, vigour is denoted by high levels of energy and mental resilience while working, the willingness to invest effort in individual work, and persistence even in the face of difficulties. Dedication refers to being strongly involved in individual work and experiencing a sense of significance, enthusiasm, inspiration, pride and challenge. Absorption is characterised by being fully concentrated and happily engrossed in one's work, whereby time passes quickly and it is difficult to detach oneself from work.
Work engagement is linked to a variety of individual and organisational outcomes; at an individual level, it is related to the mental and physical health of employees at work. Studies show that employees with higher levels of work engagement report fewer health-related complaints and higher levels of mental health (Leijten et al., 2015; Shimazu et al., 2016). At an organisational level, work engagement has been associated with important organisational outcomes; studies proved that work engagement influences job satisfaction (Alarcon \& Lyons, 2011), organisational commitment (Hallberg \& Schaufeli, 2006) and intention to quit among employees (Takawira, Coetzee \& Schreuder, 2014). This highlights the importance of work engagement at both the individual and organisational levels. Therefore, studying work engagement with the aim to identify new ways of enhancing it could lead to practical implications for both employees and organisations, especially in the public sector. Within this context, motivational levers can only be based on issues related to intrinsic motivation because it is difficult or almost impossible to use monetary incentives or motivational levers other than personal ones, i.e. cognitive and emotional resources.

Further studies show that personal resources of employees play a central role in improving their work engagement (Xanthopoulou, Bakker, Demerouti \& Schaufeli, 2007). Personal resources are aspects of the self that are generally linked to resilience and refer to individuals' sense of their ability to control and have a successful impact on their environment (Hobfoll, Johnson, Ennis \& Jackson, 2003). Some of these personal resources such as self-efficacy (Bandura, 1989), organisational-based self-esteem (Pierce, Gardner, Cummings, \& Dunham, 1989) and optimism (Scheier \& Carver, 1985) have been recognised by Hobfoll (2002) as fundamental components of individual adaptability. According to this line of research, we propose psychological capital as a personal resource, which is regarded as malleable through specific interventions among employees of the public administration. Below we present the main results of empirical studies that have investigated the relationship between psychological capital and work engagement and how this can result in positive organisational outcomes.

\section{Psychological capital and work engagement: Antecedents and consequences}

During the past three decades, several studies have shown that work engagement, originating from positive psychology concepts, has a positive impact on employee job satisfaction (Yeh, 2013), as well as on job performance (Demerouti \& Bakker, 2006). This has motivated researchers to look for potential antecedents that can predict and be utilised to improve work engagement at the workplace. They found that psychological capital is one of the antecedents derived from the same root, namely positive organisational behaviour, which represents an integration of positive psychology principles and organisational settings (Avey, Luthans, Smith \& Palmer, 2010; Youssef \& Luthans, 2007; Luthans \& Avolio, 2009). Psychological capital is mainly defined as positive psychological states of individual development, consisting of four components, namely hope, optimism, self-efficacy and 
resilience (Luthans, Youssef \& Avolio, 2007). Based on this definition, hope refers to persisting towards goals and, when necessary, redirecting paths to goals in order to succeed. Optimism means making a positive attribution about succeeding in both the present and future. Self-efficacy refers to having confidence to take on and put in enough effort to succeed at challenging tasks. Resilience is the ability to recover from setbacks, adapt well to change and keep going in the face of adversity, in order to manage difficulty at work and overcome stress.

\section{Resource-based intervention programme: A positive psychology intervention}

Although there are several different resource-based intervention programmes, scholars suggest that future studies need to test the effect of different and new interventions, tailored to target populations with a particular emphasis on resources aimed at improving outcomes (Baumeister \& Alghamdi, 2015; Ceschi, Costantini, Phillips \& Sartori, 2017). Psychological capital represents a set of cognitive resources that enables an individual to experience rewards in the present moment while also increasing the likelihood of future benefits (Luthans et al., 2007). Accordingly, we propose that psychological capital can be considered one of the personal resources capable of increasing positive work-related outcomes such as work engagement and well-being. This can be explained based on the framework provided by the Conservation of Resources Theory (COR) (Hobfoll, 1989). According to this theory, individuals seek to acquire and maintain resources to accommodate, withstand, overcome threats or improve strengths. They may accumulate material resources (e.g. homes, clothes, food), personal resources (e.g. self-esteem, selfconfidence and optimism), conditions resources (e.g. status, social support, financial security) and energy resources (e.g. time, money and knowledge).

In our resource-based intervention programme (i.e. FAMILY), psychological capital is assumed to act as a personal resource, increasing the ability of employees to tolerate job demands and experience positive mind states. Indeed, the resourcebased intervention programme focuses on the two main assumptions of the above-mentioned COR theory with respect to increasing positive job-related outcomes. The first assumption is that individuals invest in their resources in order to deal with threatening conditions and to protect themselves against negative outcomes (Hobfoll, 1989). Therefore, an improvement of personal resources by increasing psychological capital should lead to heightened resilience and self-efficacy in employees protecting them against job demands. Second, individuals not only strive to protect these resources, but also to accumulate them. Resources tend to generate other resources, thus creating resource caravans, which may result in positive outcomes, like better coping reactions and well-being (Hobfoll, 2002). Therefore, relying on what has been suggested by studies on psychological capital intervention, a proliferation in positive outcomes regarding work engagement among employees can be expected. To support this line of reasoning, we refer to the study of Bakker and Demerouti (2007) that presented a model of resources leading to work engagement (Figure 1). This provides additional evidence to suggest that psychological capital, in terms of personal resources that enhance work engagement, can be improved by utilising specific, empowering interventions.

Psychological capital dimensions may have some stability over time but, as state-like constructs, they also have the capability and flexibility to develop and grow. This means that unlike trait-like constructs, which are relatively stable and difficult to change (Ceschi, Costantini, Scalco, Charkhabi, \& Sartori, 2016; Ceschi, Sartori, Dickert, \& Costantini, 2016), psychological capital dimensions are relatively open to development (Luthans, Luthans \& Luthans 2004; Luthans et al., 2007). Preliminary research on self-efficacy, hope, optimism and resilience supports the notion that these constructs can be developed. This openness to change has encouraged researchers to design programmes and interventions in order to enhance psychological capital

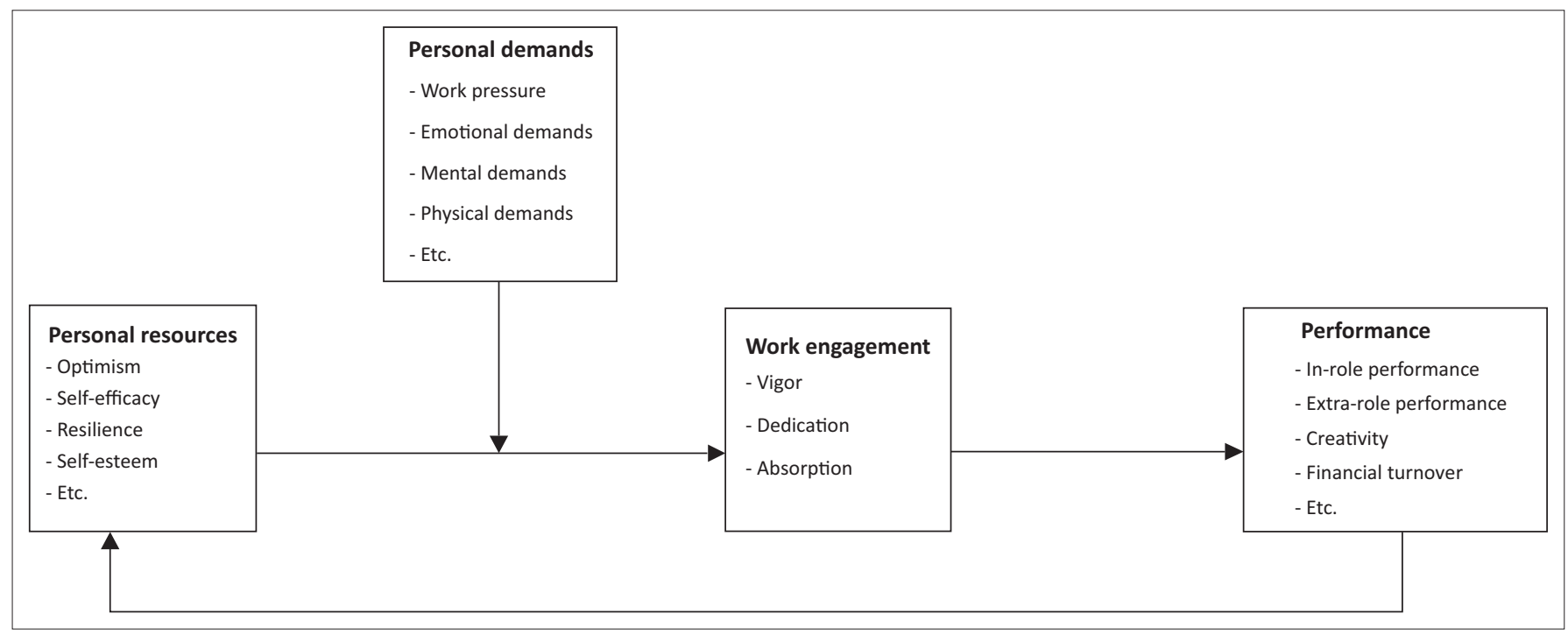

Source: Bakker, A.B., \& Demerouti, E. (2007). The job demands resources model: State of the art. Journal of Managerial Psychology, 22, 309-328. https://doi.org/10.1108/02683940710733115 FIGURE 1: The role of personal resources in work engagement. 
(Hengel, Blatter, Joling, Van der Beek \& Bongers, 2012; Van Berkel, Proper, Boot, Bongers \& Van der Beek, 2011). The majority of such interventions have been based on positive psychology principles focusing on a person's strengths (Seligman, Steen, Park \& Peterson, 2005).

Interventions can be divided into three groups, viz., (1) interventions that focus on providing an opportunity for employees in which people have the possibility to analyse themselves from different angles. This can help them find a 'best self' of themselves at work, which means to focus on strengths, contributions and enduring talents that each person brings to a situation (Roberts, Dutton, Spreitzer, Heaphy \& Quinn, 2005) and is likely to be associated with high feelings of being engaged, energised and fulfilled in one's role (Peterson \& Seligman, 2004); (2) solution-focused coaching interventions - that emphasise strengthdevelopment and solution-generation methods instead of problem analysis (Grant, 2003). In this approach, researchers try to motivate individuals by focusing on goal setting that can lead to enhancement of hope (Luthans \& Youssef, 2004) and self-efficacy, given that goal achievement is likely to influence one's global ability to meet task demands across different domains and contexts (Grant, Curtayne \& Burton, 2009); (3) interventions aimed at transferring valued organisational characteristics to individuals, by identifying life-giving forces and core strengths within the organisation to reach organisational goals. In this approach, trainers use stories of organisational successes or set up actions and plans to draw an ideal future of their organisation (Cooperrider \& Whitney, 2005). This approach also bypasses destructive processes such as negation, mutual criticism and spiralling problem diagnosis and instead creates high motivation and feelings of cooperation among organisational members (Whitney \& Cooperrider, 1998).

Reviewing these interventions inspired us to design a new intervention programme stemming from the first and second approaches in order to enhance employee psychological capital. In the new intervention, referred to as the resourcebased intervention programme (known as FAMILY intervention), the focus is on two important principles. The first is to provide employees with awareness about psychological capital and its strengths, and the second is to improve their psychological capital through various methods, exercises and practices, in order to raise their skill and strength levels in their specific work role. The methods section will provide a detailed account of the structure and content of the intervention.

\section{Hypotheses}

Although there are studies that have confirmed hope, optimism, self-efficacy and resilience as personal resources leading to improvement in work engagement (Bakker \& Demerouti, 2007), little is known about the way these four resources influence work engagement in the Italian context, particularly among public administration employees. Therefore, we will test the effect of psychological capital (hope, optimism, self-efficacy and resiliency) on work engagement and predict that psychological capital, representing the personal resources of employees, will show a positive association with their work engagement, at both before and after intervention:

Hypothesis 1 (H1): Psychological capital (hope, optimism, selfefficacy and resiliency) is positively associated with work engagement both before $\left(T_{0}\right)$ and after $\left(T_{1}\right)$ the intervention.

By the intervention proposed we believe that it is possible to achieve improvement in the level of psychological capital of employees. Because previous studies have proven that psychological capital may contribute to a reduction in negative outcomes, as well as a surge in positive results among employees (Görgens-Ekermans \& Herbert, 2013; Luthans, 2002), we predict that this intervention will result in an enhancement of both psychological capital and work engagement. This leads to the following hypotheses:

Hypothesis 2 (H2): The level of the dimensions constituting employees' psychological capital after the intervention is significantly higher than the level of the dimensions constituting employees' psychological capital before the intervention.

Hypothesis 3 (H3): The level of employee work engagement after the intervention is significantly higher than the level of employee work engagement before the intervention.

Hypothesis 4 (H4): The level of work engagement before the intervention $\left(T_{0}\right)$ will be positively associated with the level of psychological capital $\left(T_{1}\right)$ after the intervention. Moreover, psychological capital $\left(T_{0}\right)$ before the intervention will be positively associated with work engagement $\left(T_{1}\right)$ after the intervention (H4c). In the light of the relationships described in Hypothesis 1, such linkages imply a mediator role of work engagement measured before the intervention, as well as of psychological capital after the intervention.

Figure 2 shows a conceptual model of the relationship among the research variables and hypotheses used in this study.

\section{Research design Research approach}

This research is a semi-experimental study involving pretest, intervention and post-test. We used a simple random

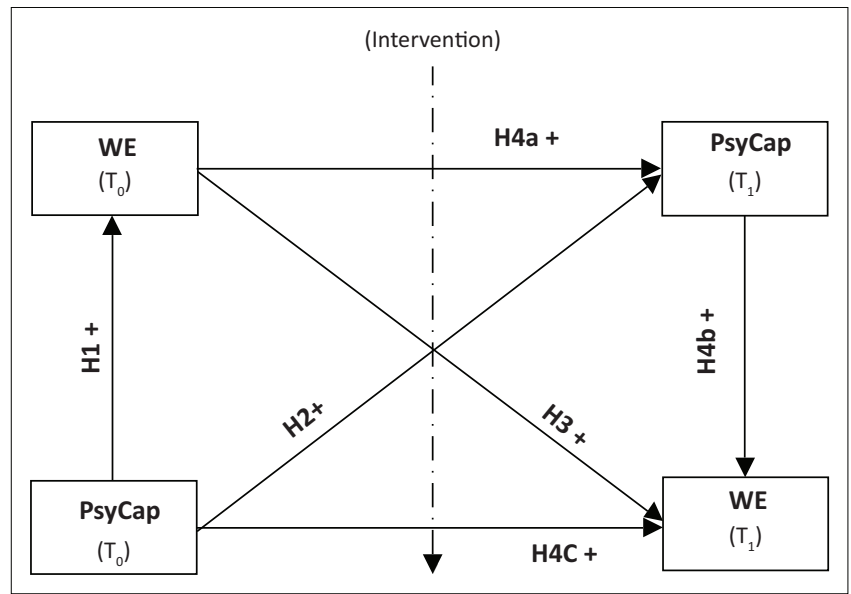

FIGURE 2: A conceptual model of the relationships among research variables. 
sampling method to select the participants, who were recruited via the intranet web site of the organisation that took part in the research project. Participants voluntarily took part in the study in which they were asked to participate in a training session aiming at enhancing well-being at work, and to fill out a questionnaire before and after such an intervention. The final sample, which was a sample of convenience, included all white-collar and blue-collar employees working in a public health administration context operating in the south of Italy. Participants received three day-long training sessions of the resources-based intervention programme (i.e. FAMILY intervention). Data in the pre-test and post-test stages were collected by using the Italian version (Alessandri, Borgogni, Consiglio \& Mitidieri, 2015) of the original 24-item Psychological Capital Questionnaire (PCQ) developed by Luthans et al. (2007) and the Italian version (Pisanti, Paplomatas, \& Bertini, 2008) of the 17-item Utrecht Work Engagement Scale developed by Schaufeli and Bakker (2003).

\section{Research method}

\section{Research participants}

In order to test our hypotheses, participants $(N=54)$ were asked to take part in the FAMILY intervention and to fill in a questionnaire before and after the intervention. Of these participants, $69.64 \%$ were females and $30.36 \%$ males. The mean age of the respondents was 54.76 years $(\mathrm{SD}=6.83)$. All participants undertook both the intervention and the questionnaire completion; therefore, no control group was available.

\section{Measuring instruments}

Psychological capital: The Italian version (Alessandri et al., 2015) of the original 24-item PCQ was used to measure four dimensions of psychological capital. Each dimension was measured by six items. Example items of this scale are: 'I have several ways to accomplish the work goal (Hope)', 'I believe that all the problems occurring at work always have a bright side (Optimism)', 'I am confident in my performance that I can work under pressure and challenging circumstances (Self-efficacy)' and 'Although too much responsibility at work make me awkward, I can go through my work successfully (Resilience)'. Respondents were asked to rate the items on a scale from 1 (totally disagree) to 6 (totally agree). Higher scores represent higher psychological capital. Principal component analyses were conducted to test the factorial validity of this measure at both pre-test and posttest. The small sample size did not permit to assess a complete confirmatory factor analysis (CFA) because it would require the estimation of too many parameters. Based on the Italian validation of the measure, we extract four factors. Before the intervention, the overall Kaiser-Meyer-Olkin test (KMO) was 0.73 and Bartlett's test of sphericity was statistically significant for $p<0.001\left[\chi^{2}(276)=809.48\right]$. The total explained variance was $61.07 \%$. Each of the four factors had six loaded variables. After the intervention, the overall KMO was 0.80, Bartlett's test of sphericity was statistically significant for $p<0.001$ $\left[\chi^{2}(276)=748.33\right]$ and the total explained variance was $61 \%$, for which the factor structure replicated the one before the intervention. The Cronbach's alpha reliability of the scale in pre-test and post-test studies was 0.87 and 0.86 , respectively.

Work engagement: Work engagement was assessed with the Italian version (Pisanti et al., 2008) of the 17-item Utrecht Work Engagement Scale developed by Schaufeli and Bakker (2003). This scale includes six items for the vigour component (e.g. 'At my work, I feel bursting with energy'), six items for the absorption component (e.g. 'I am immersed in my work') and five items for the dedication component (e.g. 'I am enthusiastic about my job'). A seven-point Likert scoring system was used for each item of this scale, with the following indicators: 'never' (score of 0) to 'always' (score of 6). As for psychological capital, principal component analyses were conducted to test the factorial validity of this measure at both pre-test and post-test. Based on the Italian validation of the measure, we extract three factors. Before the intervention, the overall $\mathrm{KMO}$ was 0.85 , and Bartlett's test of sphericity was statistically significant for $p<0.001\left[\chi^{2}(136)=610.69\right]$. The total explained variance was 65.73 . Two of the three factors each had six loaded variables, and one had five loaded variables. After the intervention, the overall $\mathrm{KMO}$ was 0.82 , Bartlett's test of sphericity was statistically significant for $p<$ $0.001\left[\chi^{2}(136)=616.26\right]$ and the total explained variance was 65.63 , for which the factor structure replicated the one before the intervention. The Cronbach's alpha of the scale in pre-test and post-test studies was 0.93 and 0.91 respectively.

Intervention content: As mentioned earlier, work engagement is a construct originating from positive psychology principles (Meyers et al., 2013) and is characterised as a positive, fulfilling, work-related state of mind (Schaufeli \& Bakker, 2003). Based on current evidence, personal resources of employees, such as psychological capital, play a central role in the development of work engagement. For instance, Xanthopoulou et al. (2007) found that an increase in the psychological capital of employees is consistent with an increase in their work engagement. Therefore, in order to enhance work engagement, we developed an intervention programme directed at improving four indicators of psychological capital (hope, optimism, self-efficacy and resiliency). We were inspired by the COR theory (Hobfoll, 1989) to develop the content of this intervention. Based on this theory, according to which individuals with more personal resources are more likely to overcome challenges and experience more positive outcomes at work, an intervention programme focused on a number of positive reappraisals of the work role was developed. It consists of six steps that were expected to lead to improvements in psychological capital and work engagement (Figure 3). The total duration of the intervention was one week and there were three day-long sessions in which the intervention content was presented according to the following steps:

- Step 1: Framing (F) refers to the framing concept, or helping individuals to focus on the positive rather than on the negative aspects of work. Re-framing is also a 


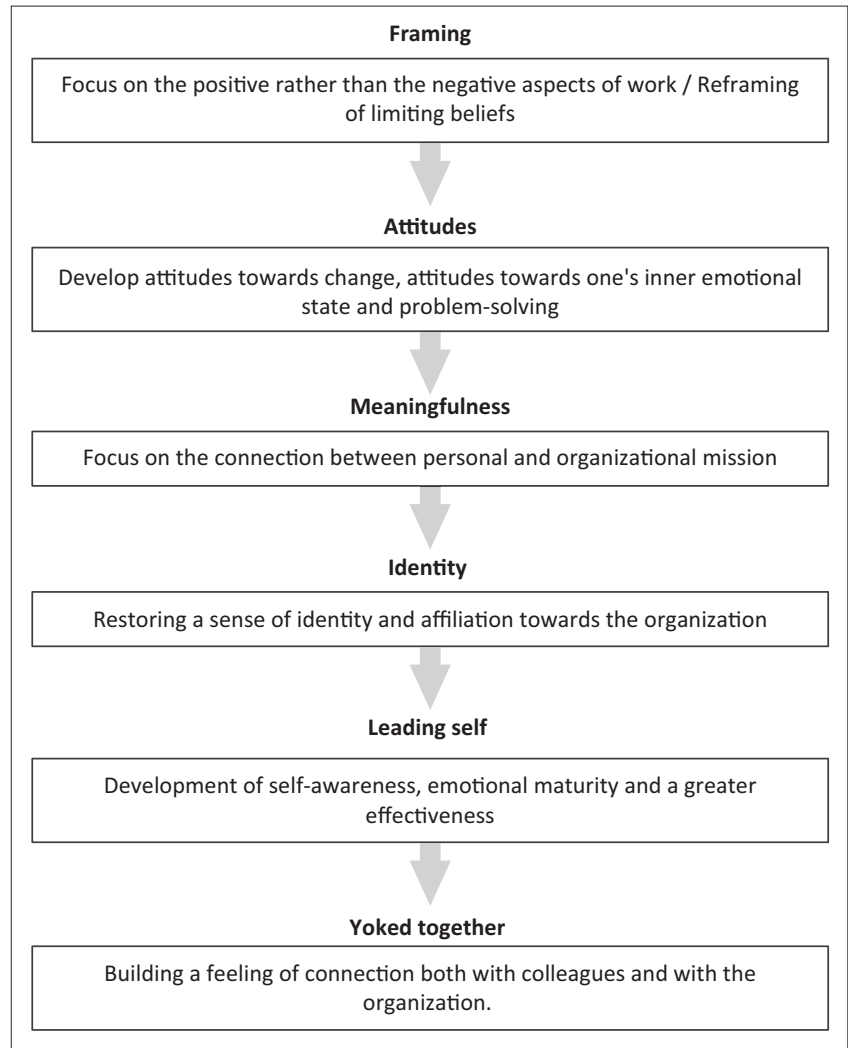

FIGURE 3: A summarised graph of the content of each step of the intervention.

cognitive process that can transform limiting beliefs and reframe negative experiences by changing the meanings attributed to them and allowing participants to learn from their experience in order to take advantage for the purposes of their daily work by adopting a new way of looking at things.

- Step 2: Attitudes (A) refer to the appropriate attitudes that participants should be taught, to develop and reach the desired level of engagement, well-being and performance. Employees are trained to look at each situation from a positive perspective, i.e. perceiving situations as opportunities for gaining and growth rather than perceiving situations in a threatening way.

- Step 3: Meaningfulness (M) is what would typically be referred to as psychological meaningfulness at work. In this step, the idea is to enhance a sense of meaning and purpose in one's personal life, connecting it to the organisational mission. In this intervention, the researchers struggled to strengthen the connection between personal and organisational mission, in order to make them jointly develop.

- Step 4: Identity (I) aims to restore a sense of identity and affiliation with respect to the organisation. The coach delves deeper into the personal domain, enquiring about feelings and perceptions of self-identity, referring to individual aspirations within the organisational context. Part of the intervention entails the development of a 'new self', as an employee, with a better fit with the work role and other more specific aspects of the environment.

- Step 5: Leading self (L) is related to the development of self-awareness, emotional maturity and greater effectiveness. This falls within the scope of learning to become the leader of oneself and taking on responsibility for each aspect of daily work life, dealing with stressful and negative events in positive ways.

- Step 6: Yoked together (Y) aims to build a feeling of connection both with colleagues (at team level) and with the organisation (at a broader level). The term of 'yoked' means 'being linked together by means of'. In the organisational context, the expression points to a sense of belonging and alignment to be instilled and nurtured, so that each individual feels that he or she is part of something greater than themselves, moving towards a common purpose, while being fully aware of the importance of being connected.

\section{Research procedure and ethical considerations}

This intervention was designed for the duration of a week and based on a one day-on (day of participation) and one day-off (day of rest) sequence. The material of this training programme was presented during three day-long sessions. In these sessions, each participant was requested to carefully follow the intended structure. The first part of this structure was 'goal setting' in which the trainer encouraged participants to set goals with respect to the topic of that particular session. The second part was 'training', in which the trainer explained the content of the workshop, its value in ensuring employee engagement and well-being, and utility in improving the new skills required. The next part involved an 'exercise' in which the trainer gave relevant, simple and challenging exercises to participants for them to work on individually or in groups. In the 'feedback' phase, the trainer gave performance feedback to the participants regarding the exercises. This part continued with a conversation between trainer and participants in which the trainer tried to provide other practical examples to improve the participants' comprehension. In the last part, called 'control', once the level of understanding and skills acquisition of the participants had been checked, the trainer encouraged them to continue pursuing new and more challenging goals, thus creating a virtuous cycle of continuous improvement. This phase concluded with an interview between the trainer and participants, in which the trainer provided additional practical examples to improve participants' understanding.

The research staff provided participants with the questionnaire and explained the anonymous nature of the data collection during the instructions. Anonymity (pre-test and post-test) was guaranteed through the insertion of an identification code that each respondent had to include in the initial part of the questionnaire. This identification code was formed by the initial letters (three) of a significant person and objects of the respondent's life, that together constitute a code of nine letters that can be used to match the pre-test and post-test respondent questionnaire. Furthermore, participants were requested to take part in the surveys in the absence of organisational officials; but completed the survey during working hours. Pre-intervention questionnaires were distributed by the researchers on Monday of the week before 
the intervention. Each participant returned the questionnaire in a sealed envelope by Friday of the week before the intervention. Post-intervention questionnaires were distributed to the participants on Monday of the first week after the intervention, and returned by Friday of the same week in a sealed envelope.

\section{Statistical analysis}

$t$-Tests, mediated regression technique and bootstrapping following the PROCESS procedure recommended by Hayes (2013) were used to test the hypotheses.

\section{Results}

The descriptive statistics pertaining to the research variables, which include means and standard deviations, as well as the Pearson correlations among the variables, are reported in Table 1. These correlations are reported based on the pre-test $\left(T_{0}\right)$ and post-test $\left(T_{1}\right)$ steps. As Table 1 shows, in the pre-test there is a significant correlation between psychological capital and work engagement $(r=0.65, p<0.001)$. This means that an increase in psychological capital is consistent with an increase in work engagement. The dimensions of hope $(r=0.63, p<0.01)$ and self-efficacy $(r=0.60, p<0.01)$ have the highest correlations with work engagement, while optimism $(r=0.34, p<0.05)$ and resilience $(r=0.44, p<0.01)$ have the lowest correlations with work engagement. The positive association between psychological capital and work engagement in the pre-test $(r=0.65, p<0.01)$ was replicated in the post-test step $(r=0.65, p<0.01)$. Furthermore, similar to the pre-test, in the post-test hope $(r=0.76, p<0.01)$ and self-efficacy $(r=0.55, p<0.01)$ had stronger correlations with work engagement compared to optimism $(r=0.47, p<$ $0.01)$ and resilience $(r=0.48, p<0.001)$. This provides additional support for $\mathrm{H} 1$, providing overall confirmation for it.

\section{The relationship between psychological capital and work engagement}

Hypothesis 1 stated that the dimensions constituting psychological capital are positively related to work engagement at both $T_{0}$ and $T_{1}$. Before the intervention, results from multiple regression analyses (see Table 2) revealed a significant positive beta coefficient only for the dimensions of hope $(\beta=0.39, p<0.01)$ and self-efficacy $(\beta=0.36, p<0.01)$ predicting the overall index of work engagement. After the intervention, only the dimension of hope was found to be a significant predictor of the overall index of work engagement $(\beta=0.59, p<0.01)$, hence providing partial support for $\mathrm{H} 1$.

\section{Effects of the intervention}

In order to test $\mathrm{H} 2$, which stated that the participants' levels of psychological capital will be significantly increased after the training $\left(T_{1}\right)$, as opposed to their level prior to training $\left(T_{0}\right)$, a paired-sampled $t$-test was used. This tested the significance of the difference between the measures at $T_{0}$ and at $T_{1}$. The same method was used to test $H 3$, which stated

TABLE 2: Multiple regression analysis results for PsyCap predicting work engagement before and after the intervention $(N=54)$.

\begin{tabular}{lccc}
\hline Variable & $\boldsymbol{\beta}$ & B & $\boldsymbol{p}$ \\
\hline Before the intervention & & & \\
Hope & 0.39 & 0.39 & 0.00 \\
Resilience & 0.03 & 0.03 & 0.82 \\
Optimism & -0.01 & -0.01 & 0.97 \\
Self-efficacy & 0.36 & 0.33 & 0.01 \\
$R^{2}$ & 0.51 & & $<0.001$ \\
After the intervention & & & \\
Hope & 0.59 & 0.62 & 0.01 \\
Resilience & 0.07 & 0.08 & 0.59 \\
Optimism & 0.05 & 0.05 & 0.72 \\
Self-efficacy & 0.05 & 0.05 & 0.72 \\
$R^{2}$ & 0.52 & & $<0.001$ \\
\hline
\end{tabular}

Note: Age has been controlled for.

$\beta$, standardised beta-coefficients; $B$, unstandardised coefficients; $R^{2}$, explanation rate.

TABLE 1: Means, standard deviations (SD) and intercorrelations among the study variable $(N=54)$.

\begin{tabular}{|c|c|c|c|c|c|c|c|c|c|c|c|c|c|c|c|c|c|c|c|c|c|c|}
\hline Time & $\begin{array}{l}\text { Variable } \\
\text { number }\end{array}$ & Variable & $M$ & SD & 1 & 2 & 3 & 4 & 5 & 6 & 7 & 8 & 9 & 10 & 11 & 12 & 13 & 14 & 15 & 16 & 17 & 18 \\
\hline \multirow[t]{5}{*}{$T_{0}$} & 1 & Hope & 3.99 & 0.91 & - & - & - & - & - & - & - & - & - & - & - & - & - & - & - & - & - & - \\
\hline & 2 & Resilience & 4.16 & 0.81 & $0.59^{* *}$ & - & - & - & - & - & - & - & - & - & - & - & - & - & - & - & - & - \\
\hline & 3 & Optimism & 3.60 & 0.95 & $0.43^{* *}$ & $0.43^{* *}$ & - & - & - & - & - & - & - & - & - & - & - & - & - & - & - & - \\
\hline & 4 & Self-efficacy & 4.46 & 0.96 & $0.54^{* * *}$ & $0.47^{* *}$ & $0.43^{* *}$ & - & - & - & - & - & - & - & - & - & - & - & - & - & - & - \\
\hline & 5 & PsyCap & 4.05 & 0.71 & $0.82^{* *}$ & $0.78^{* * *}$ & $0.74^{* * *}$ & $0.79^{* *}$ & - & - & - & - & - & - & - & - & - & - & - & - & - & - \\
\hline \multirow[t]{5}{*}{$T_{1}$} & 6 & Hope & 4.61 & 0.78 & $0.72^{* *}$ & $0.65^{* *}$ & $0.41^{* * *}$ & $0.59^{* * *}$ & $0.76^{* *}$ & - & - & - & - & - & - & - & - & - & - & - & - & - \\
\hline & 7 & Resilience & 4.30 & 0.75 & $0.42^{* *}$ & $0.70^{* * *}$ & 0.21 & $0.38^{* * *}$ & $0.53^{* * *}$ & $0.57^{* *}$ & - & - & - & - & - & - & - & - & - & - & - & - \\
\hline & 8 & Optimism & 4.41 & 0.84 & $0.54^{* * *}$ & $0.46^{* * *}$ & $0.70^{* * *}$ & $0.56^{* *}$ & $0.74^{* *}$ & $0.61^{* *}$ & $0.46^{* *}$ & - & - & - & - & - & - & - & - & - & - & - \\
\hline & 9 & Self-efficacy & 4.81 & 0.80 & $0.53^{* *}$ & $0.56^{* * *}$ & $0.27^{*}$ & $0.83^{* * *}$ & $0.70^{* * *}$ & $0.66^{* *}$ & $0.42^{* *}$ & $0.53^{* * *}$ & - & - & - & - & - & - & - & - & - & - \\
\hline & 10 & PsyCap & 4.52 & 0.61 & $0.68^{* * *}$ & $0.67^{* *}$ & $0.54^{* * *}$ & $0.72^{* *}$ & $0.86^{* *}$ & $0.85^{* *}$ & $0.70^{* *}$ & $0.83^{* * *}$ & $0.78^{* *}$ & - & - & - & - & - & - & - & - & - \\
\hline \multirow[t]{4}{*}{$T_{0}$} & 11 & Vigour & 4.69 & 0.96 & $0.58^{* *}$ & $0.44^{* * *}$ & $0.36^{* *}$ & $0.63^{* *}$ & $0.65^{* *}$ & $0.73^{* *}$ & $0.46^{* *}$ & $0.46^{* *}$ & $0.59^{* * *}$ & $0.72^{* * *}$ & - & - & - & - & - & - & - & - \\
\hline & 12 & Dedication & 4.93 & 0.92 & $0.66^{* *}$ & $0.44^{* * *}$ & $0.33^{* * *}$ & $0.62^{* *}$ & $0.66^{* *}$ & $0.67^{* *}$ & $0.40^{* *}$ & $0.43^{*}$ & $0.63^{* *}$ & $0.64^{* *}$ & $0.85^{* * *}$ & - & - & - & - & - & - & - \\
\hline & 13 & Absorption & 4.48 & 1.06 & $0.48^{* *}$ & $0.32^{*}$ & 0.24 & $0.39^{* * *}$ & $0.46^{* * *}$ & $0.59^{* *}$ & $0.42^{* *}$ & 0.28 & $0.38^{* * *}$ & $0.51^{* *}$ & $0.75^{* *}$ & $0.76^{* *}$ & - & - & - & - & - & - \\
\hline & 14 & WE & 4.74 & 0.90 & $0.63^{* *}$ & $0.44^{* *}$ & $0.34^{*}$ & $0.60^{* *}$ & $0.65^{* *}$ & $0.72^{* *}$ & $0.46^{* *}$ & $0.43^{* *}$ & $0.59^{* *}$ & $0.68^{* *}$ & $0.94^{* *}$ & $0.95^{* *}$ & $0.88^{* *}$ & - & - & - & - & - \\
\hline \multirow[t]{4}{*}{$T_{1}$} & 15 & Vigour & 5.09 & 0.84 & $0.62^{* *}$ & $0.53^{* *}$ & $0.37^{* *}$ & $0.65^{* * *}$ & $0.69^{* *}$ & $0.79^{* *}$ & $0.57^{* *}$ & $0.52^{* *}$ & $0.62^{* *}$ & $0.74^{* * *}$ & $0.80^{* * *}$ & $0.75^{* *}$ & $0.58^{* *}$ & $0.78^{* *}$ & - & - & - & - \\
\hline & 16 & Dedication & 5.25 & 0.81 & $0.68^{* * *}$ & $0.47^{* *}$ & $0.28^{*}$ & $0.54^{* * *}$ & $0.63^{* *}$ & $0.69^{* *}$ & $0.41^{* *}$ & $0.46^{*}$ & $0.60^{* * *}$ & $0.65^{* *}$ & $0.77^{* * *}$ & $0.88^{* *}$ & $0.62^{* *}$ & $0.83^{* * *}$ & $0.85^{* * *}$ & - & - & - \\
\hline & 17 & Absorption & 4.61 & 0.98 & 0.25 & 0.16 & 0.25 & $0.33^{*}$ & $0.33^{*}$ & $0.41^{* *}$ & $0.28^{*}$ & 0.23 & 0.17 & 0.28 & $0.50^{* *}$ & $0.53^{* *}$ & $0.56^{* *}$ & $0.56^{* *}$ & $0.61^{* * *}$ & $0.57^{* *}$ & - & - \\
\hline & 18 & WE & 5.04 & 0.77 & $0.61^{* * *}$ & $0.46^{* *}$ & $0.34^{*}$ & $0.59^{* * *}$ & $0.64^{* * *}$ & $0.73^{* *}$ & $0.48^{* *}$ & $0.47^{* *}$ & $0.55^{* *}$ & $0.65^{* * *}$ & $0.79^{* * *}$ & $0.83^{* *}$ & $0.66^{* *}$ & $0.83^{* *}$ & $0.94^{* * *}$ & $0.93^{* *}$ & $0.78^{* * *}$ & - \\
\hline
\end{tabular}

$*, p<0.05 ; * *, p<0.01$

$\mathrm{T}_{0^{\prime}}$ Time 0; $\mathrm{T}_{1}$, Time 1; PsyCap, Psychological Capital; WE, Work engagement. 
that work engagement would have improved after training. As can be seen in Table 3, a significant mean difference on all variables except one (i.e. absorption) was found between $T_{0}$ and $T_{1}(p<0.001)$. Regarding psychological capital, the most noticeable change occurred with optimism, having the largest mean difference among the dimensions considered (-0.91) and effect size (-1.36). Regarding work engagement, results reveal that vigour showed the largest mean difference $(-0.40)$, dedication reported the largest effect size $(-0.75)$, while the mean difference referred to the dimension of absorption was not statistically significant. These results confirmed $\mathrm{H} 2$ and partially confirmed $\mathrm{H} 3$.

\section{The mediating role of psychological capital and work engagement}

Hypothesis 4 stated that work engagement at $T_{0}$ and psychological capital at $T_{1}$ would be positively related to psychological capital at $T_{0}$ and work engagement at $T_{1}$ respectively. In the light of the preceding analyses showing that psychological capital is positively associated with work engagement, we tested this hypothesis in order to investigate the mediator role of work engagement at $T_{0}$ and psychological capital at $T_{1}$. That is, we tested whether psychological capital at $T_{0}$ is linked to psychological capital at $T_{1}$ through the mediation of work engagement at $T_{0^{\prime}}$ and whether work engagement at $T_{0}$ is linked to work engagement at $T_{1}$ through a mediation of psychological capital at $T_{1}$.

These mediation hypotheses were tested following the PROCESS procedure recommended by Hayes (2013), by using the overall measures for both psychological capital and work engagement. Prior to testing we mean centred all variables.

First of all, bootstrapping revealed a significant total effect $95 \%$ CI $(0.368,1.024)$ of psychological capital at $T_{0}$ on work engagement at $T_{1}$. Work engagement and psychological capital at $T_{0}$ significantly predicted psychological capital at $T_{1}$. Bootstrapping also revealed that the indirect effects of work engagement at $T_{0}$ is significant $[95 \%$ CI $(0.357,0.827)]$ only when considering the whole pattern of mediation hypothesised, that is considering also the role of psychological capital both before and after the intervention. In the light of these results, $\mathrm{H} 4$ is partially confirmed, in particular concerning the mediating role of work engagement at $T_{0}$ in

TABLE 3: Paired sample $t$-test results for PsyCap dimensions and overall index and work engagement dimensions and overall index on time 0 and time $1(N=54)$.

\begin{tabular}{lccccc}
\hline Variables & M difference & $\boldsymbol{D}$ & $\boldsymbol{t}$ & $\boldsymbol{d} \boldsymbol{f}$ & $\boldsymbol{p}$ \\
\hline Hope $T_{0}-T_{1}$ & -0.62 & -0.98 & -7.07 & 53 & $<0.001$ \\
Resilience $T_{0}-T_{1}$ & -0.14 & -0.23 & -1.64 & 53 & 0.107 \\
Optimism $T_{0}-T_{1}$ & -0.91 & -1.36 & -9.38 & 53 & $<0.001$ \\
Self-efficacy $T_{0}-T_{1}$ & -0.34 & -0.66 & -4.65 & 53 & $<0.001$ \\
PsyCap $T_{0}-T_{1}$ & -0.54 & -1.61 & -10.88 & 53 & $<0.001$ \\
Vigour $T_{0}-T_{1}$ & -0.40 & -0.70 & -4.99 & 53 & $<0.001$ \\
Dedication $T_{0}-T_{1}$ & -0.32 & -0.75 & -5.27 & 53 & $<0.001$ \\
Absorption $T_{0}-T_{1}$ & -0.13 & -0.14 & -1.03 & 53 & 0.307 \\
Work engagement $T_{0}-T_{1}$ & -0.30 & -0.62 & -4.42 & 53 & $<0.001$ \\
\hline
\end{tabular}

$T_{0^{\prime}}$ Time $0 ; T_{1}$, Time 1 . the relationship between psychological capital at $T_{0}$ and work engagement at $T_{1}$.

\section{Discussion Outline of the results}

Public organisations need public servants who feel energised, are dedicated and absorbed in their work, i.e. workers who are physically and mentally engaged (Vigoda-Gadot, Eldor \& Schohat, 2012). In the first part of this study, we investigated the association between psychological capital and work engagement to identify the extent to which the dimensions of psychological capital could influence employees' levels of work engagement in the workplace. Findings revealed a positive association between such constructs considered both before and after the intervention. This indicates that psychological capital has a strong connection and common root with work engagement, and that individuals high on psychological capital are more likely to be engaged at work.

Further findings showed that not all dimensions of psychological capital influence work engagement in the same way. For example, as the result of multiple regression analysis revealed, the dimension of hope showed the maximum predictive variance in explaining work engagement. It means that individuals high on hope might be more engaged in their work. Hope refers to persevering towards goals and, when necessary, redirecting paths to goals in order to succeed (Luthans et al., 2007). According to the COR theory, it seems that hope, as a positive personal resource, inspires employees to overcome work challenges and to show higher persistence in reaching organisational goals. Considering both pre-test and post-test, the other dimensions of psychological capital were not significant predictors of work engagement.

In the second part of this study, we focused on conducting a training programme directed at fostering a number of positive reappraisals of the work role, some of which are even directly focused upon work engagement and psychological capital. The results of paired tests in the pre-test and post-test indicated that our intervention significantly increased psychological capital and its subsequent outcome namely, work engagement. Although the findings revealed that all dimensions of psychological capital were improved by the intervention, it seems that this intervention had a stronger positive influence on the dimension of optimism. Also, findings show that not all the dimensions of work engagement were equally influenced by the intervention. Accordingly, the intervention enhanced only two dimensions of work engagement, namely vigour and dedication; a greater positive effect on vigour was observed. Such results may be related to the content of the intervention, which incorporates a relevant part focusing on the enhancement of optimistic individual dispositions (i.e. Steps 1 and 2), rather than, for example, on increasing individual coping strategies that might be specifically related to higher self-efficacy and resiliency. In addition, the intervention here presented prompts to develop a proactive mind-set, aiming at stimulating participants towards the creation of their own positive work experience. 
That is, it is likely that such an approach may account for higher levels of vigour, rather than for dedication or absorption which represent less proactive dimensions of work engagement. Furthermore, the comparison of paired test results between psychological capital and work engagement indicated that this intervention influenced psychological capital more than work engagement. This is consistent with the COR theory which suggests that improvements in individuals' personal resources can help them overcome job demands and experience positive outcomes such as work engagement at work. It should be noted, however, that the conclusions we draw from the present research are based on a homogenous sample of Italian participants from a single public organisation, which is likely to be characterised by a unique set of job demands and resources, here not considered, that may vary across different occupational groups in the public sector. In these regards, future research could investigate whether and how the intervention presented here would perform differently across various occupational groups in the public sector, in order to test its effectiveness among a wider range of different public organisations (i.e. government, public academic institutions, law-enforcement agencies).

\section{Practical implications}

Outcomes of the study have practical significance for public administration in Italy. Firstly, the current Italian law prohibits the use of economic incentives as tools to motivate employees; hence, researchers have been encouraged to find alternative ways to motivate the Italian workforce. Secondly, bureaucracy in Italian organisations blocks researchers and practitioners from conducting interventions which demand extensive internal changes. This initiative encourages future studies and researchers to focus on designing interventions directed at enhancing personal resources that have the potential to increase work engagement at the individual level. Interventions such as the one presented here, which focus on improving employees by building their strengths (inner resources), may be viewed as bottom-up interventions, leading to positive outcomes for both employees and organisations. In this regard, work and organisational psychologists would benefit from the adoption of such interventions within the public sector in that they maximise employee functioning taking into account individual differences related to the way that employees approach their own work experiences. The changes in reality urge practitioners to implement interventions supporting employees in their ability to better cope with changes in both the internal and external organisational environment, being with that able to face increasing demands and innovation challenges.

\section{Limitations and recommendations}

This study has the following limitations: Firstly, the sample size was relatively small, which might have reduced the statistical power of our analyses and decreased the opportunity to generalise the results to the entire working population. Secondly, data were derived entirely from selfreport questionnaires; therefore, common method variance may have influenced our results (Podsakoff, MacKenzie, Lee, \& Podsakoff, 2003). Future research should investigate whether individual perceptions and outcomes of the intervention are shared by the entire organisation. Thirdly, all participants of the study were Italian, possibly undermining the generalisability of the findings to other nationalities. Future cross-cultural research is needed to examine whether the aforementioned intervention would produce the same results when used in the public administration domains of other nations. In addition, future longitudinal research could consider the staying power or longevity of the outcomes of the intervention examining how long engagement levels are to be sustained post-intervention. Moreover, this study shows that the FAMILY programme is potentially valuable with respect to enhancing both psychological capital and work engagement. Although the statistical technique used in this study supported the mediating effects hypothesised, it is also possible that prior levels of psychological capital and work engagement would influence the receptiveness of the participants for the content imparted by the programme. Future studies could consider alternative strategies to investigate the impact of prior levels of psychological capital and work engagement in order to deepen our knowledge of the mediating effects tested in this contribution. The study presented here is quantitative in nature. Even though such a methodological choice offers important insights to understand the relationships between positive organisational interventions, individual differences and work-related wellbeing, future studies by using qualitative methods could provide acumens to understand the influence of extraneous variables.

\section{Conclusion}

Overall, this study provided initial evidence for the proposed intervention to improve work engagement through positively influencing the indicators of psychological capital of employees in the workplace. Psychological capital plays an active and dynamic role in boosting employees' levels of work engagement. Improving employees' personal resources not only enhances their ability to deal with job demands more efficiently, but also contributes to experiencing positive states, such as work engagement at work. Indeed, enhancing work engagement through improvements made to an individual's psychological capital is the unique contribution of our systematic intervention, which was successfully performed in terms of the stated goals of the intervention.

This study contributes to literature in I/O psychology, providing evidence of the importance of training interventions in improving the personal resources of employees, which in turn relates to higher levels of work engagement. The study's intervention was a unique strategy to enhance Italian employees' levels of work engagement; seeing that such an outcome, in Italy's public sector, cannot be stimulated through compensation systems or structural organisational re-design. It is especially in these work environments that 
interventions based on the psychological involvement of the individual are regarded as critical to the success of attempts to prevent disengagement and exhaustion.

\section{Acknowledgements Competing interests}

The authors declare that they have no financial or personal relationship(s) which may have inappropriately influenced them in writing this article.

\section{Authors' contributions}

F.D.P. and A.C. were the project leaders, A.C., F.D.P. and A.C. were responsible for intervention and project design. F.D.P. performed most of the intervention. R.S. and A.M.M. made conceptual contributions. A.C., F.D.P. and A.C. prepared the dataset and performed calculations. A.C., F.D.P. and A.C. wrote the manuscript.

\section{References}

Alarcon, G.M., \& Lyons, J.B. (2011). The relationship of engagement and job satisfaction in working samples. The Journal of Psychology, 145, 463-480. https:// doi.org/10.1080/00223980.2011.584083

Alessandri, G., Borgogni, L., Consiglio, C., \& Mitidieri, G. (2015). Psychometric properties of the Italian version of the psychological capital questionnaire. International Journal of Selection and Assessment, 23, 149-159. https://doi. org/10.1111/ijsa.12103

Avey, J.B., Luthans, F., Smith, R.M., \& Palmer, N.F. (2010). Impact of positive psychological capital on employee well-being over time. Journal of Occupational Health Psychology, 15, 17-28. https://doi.org/10.1037/a0016998

Bakker, A.B., \& Demerouti, E. (2007). The job demands resources model: State of the art. Journal of Managerial Psychology, 22, 309-328. https://doi. org/10.1108/02683940710733115

Bakker, A.B., \& Demerouti, E. (2008). Towards a model of work engagement. Career Development International, 13, 209-223. https://doi.org/10.1108/136204 30810870476

Bandura, A. (1989). Regulation of cognitive processes through perceived self-efficacy. Developmental Psychology, 25, 729-735. https://doi.org/10.1037/0012-1649. 25.5.729

Baumeister, R.F., \& Alghamdi, N. (2015). Resource-based interventions in the workplace: Integration, commentary, and recommendations. Journal of Occupational and Organizational Psychology, 88, 623-629. https://doi.org/ 10.1111/joop.12130

Ceschi, A., Costantini, A., Phillips, S.D., \& Sartori, R. (2017). The career decision making competence: A new construct for the career realm. European Journal of Training and Development, 41, 8-27. https://doi.org/10.1108/EJTD-072016-0047

Ceschi, A., Costantini, A., Scalco, A., Charkhabi, M., \& Sartori, R. (2016). The relationship between the big five personality traits and job performance in business workers and employees' perception. International Journal of Business Research, 16, 63-76. https://doi.org/10.18374/IJBR-16-2.5

Ceschi, A., Sartori, R., Dickert, S., \& Costantini, A. (2016). Grit or honesty-humility? New insights into the moderating role of personality between the health impairment process and counterproductive work behavior. Frontiers in Psychology, 7, 1799. https://doi.org/10.3389/fpsyg.2016.01799

Cooperrider, D.L., \& Whitney, D. (2005). Appreciative inquiry: A positive revolution in change. San Francisco, CA: Berrett-Koehler.

Cristofoli, D., Nasi, G., Turrini, A., \& Valotti, G. (2011). Civil service reforms in Italy: The importance of external endorsement and administrative leadership. Governance, 24, 261-283. https://doi.org/10.1111/j.1468-0491.2011.01524.x

Demerouti, E, \& Bakker, A.B. (2006). Employee well-being and job performance: Where we stand and where we should go. In S McIntyre \& J Houdmont (Eds.) Occupational Health Psychology: European Perspectives on Research, Education, and Practice (vol. 1 pp. 83-111). Castelo da Maia, Port: ISMAI.

Goodsell, C. (2003). The case for bureaucracy (4th edn.). Chatham, NJ: Chatham House.

Görgens-Ekermans, G., \& Herbert, M. (2013). Psychological capital: Internal and external validity of the Psychological Capital Questionnaire (PCQ-24) on a South African sample. SA Journal of Industrial Psychology, 39, 1-12. https://doi. org/10.4102/sajip.v39i2.1131

Grant, A.M. (2003). The impact of life coaching on goal attainment, metacognition and mental health. Social Behavior and Personality, 31, 253-264. https://doi. org/10.2224/sbp.2003.31.3.253
Grant, A.M., Curtayne, L., \& Burton, G. (2009). Executive coaching enhances goal attainment, resilience and workplace well-being: A randomised controlled study. The Journal of Positive Psychology, 4, 396-407. https://doi.org/10.1080/ The Journal of Positi
17439760902992456

Hallberg, U.E., \& Schaufeli, W.B. (2006). 'Same same' but different? European Psychologist, 11, 119-127. https://doi.org/10.1027/1016-9040.11.2.119

Hayes, A.F. (2013). Introduction to mediation, moderation, and conditional process analysis: A regression-based approach. New York, NY: Guilford Press.

Hengel, K.M.O., Blatter, B.M., Joling, C.I., van der Beek, A.J., \& Bongers, P.M. (2012) Effectiveness of an intervention at construction worksites on work engagement social support, physical workload, and need for recovery: Results from a cluster randomized controlled trial. BMC Public Health, 12, 1008.

Hobfoll, S.E. (1989). Conservation of resources: A new attempt at conceptualizing stress. American Psychologist, 44, 513-524. https://doi.org/10.1037/0003-066X. 44.3.513

Hobfoll, S.E. (2002). Social and psychological resources and adaptation. Review of General Psychology, 6, 307-324. https://doi.org/10.1037/1089-2680.6.4.307

Hobfoll, S.E., Johnson, R.J., Ennis, N., \& Jackson, A.P. (2003). Resource loss, resource gain, and emotional outcomes among inner city women. Journal of Personality and Social Psychology, 84, 632-643. https://doi.org/10.1037/0022-3514.84.3.632

Jacobson, W.S. (2011). Creating a motivated workforce: How organizations can enhance and develop public service motivation (PSM). Public Personnel Management, 40, 215-238. https://doi.org/10.1177/009102601104000303

Leijten, F.R., Van den Heuvel, S.G., Van der Beek, A.J., Ybema, J.F., Robroek, S.J., \& Burdorf, A. (2015). Associations of work-related factors and work engagement with mental and physical health: A 1-year follow-up study among older workers. Journal of Occupational Rehabilitation, 25, 86-95. https://doi.org/10.1007/ s10926-014-9525-6

Luthans, F. (2002). The need for and meaning of positive organizational behavior Journal of Organizational Behavior, 23, 695-706. https://doi.org/10.1002/job.165

Luthans, F., \& Avolio, B.J. (2009). The "point" of positive organizational behavior Journal of Organizational Behavior, 30, 291-307. https://doi.org/10.1002/ job.589

Luthans, F., Luthans, K.W., \& Luthans, B.C. (2004). Positive psychological capital Beyond human and social capital. Business Horizons, 47, 45-50. https://doi. org/10.1016/j.bushor.2003.11.007

Luthans, F., \& Youssef, C.M. (2004). Human, social, and now positive psychological capital management: Investing in people for competitive advantage. Organizational Dynamics, 33, 143-160.

Luthans, F., Youssef, C.M., \& Avolio, B.J. (2007). Psychological capital: Investing and developing positive organizational behavior. In D.L. Nelson \& C.L. Cooper (Eds.), Positive organizational behavior (pp. 9-24). New York: Oxford University Press.

Merlicco, E. (2008). The Italian public administration: Ideas for innovation. Unpublished master's thesis. University of Malta, Msida, Malta.

Meyers, M.C., Van Woerkom, M., \& Bakker, A.B. (2013). The added value of the positive: A literature review of positive psychology interventions in organizations. European Journal of Work and Organizational Psychology, 22, 618-632. https:// doi.org/10.1080/1359432X.2012.694689

Osborne, D. \& Gaebler, T. (1992). Reinventing government: How the entrepreneurial spirit is transforming the public sector. Reading, MA: Addison-Wesley.

Peterson, C., \& Seligman, M.E.P. (2004). Character strengths and virtues: A classification and handbook. New York: Oxford University Press.

Pierce, J.L., Gardner, D.G., Cummings, L.L., \& Dunham, R.B. (1989). Organization-based self-esteem: Construct definition, measurement, and validation. Academy of Management Journal, 32, 622-648. https://doi.org/10.2307/256437

Pipan, T. (2000). Metaphors and organizational identity in the Italian public services. Scandinavian Journal of Management, 16, 391-409. https://doi.org/10.1016/ S0956-5221(00)00014-2

Pisanti, R., Paplomatas, A., \& Bertini, M. (2008). Misurare le dimensioni positive nel lavoro in sanità: Un contributo all'adattamento italiano della UWES-Utrecht Work Engagement Scale. Giornale Italiano di Medicina del Lavoro ed Ergonomia, 30 Engagement

Podsakoff, P.M., MacKenzie, S.M., Lee, J., \& Podsakoff, N.P. (2003). Common method variance in behavioral research: A critical review of the literature and recommended remedies. Journal of Applied Psychology, 88, 879-903. https://doi. recommended remedies. Journal of

Roberts, L.M., Dutton, J.E., Spreitzer, G.M., Heaphy, E.D., \& Quinn, R.E. (2005) Composing the reflected best-self-portrait: Building pathways for becoming extraordinary in work organizations. Academy of Management Review, 30, extraordinary in work organizations. Academy of Mant
712-736. https://doi.org/10.5465/AMR.2005.18378874

Saks, A.M. (2006). Antecedents and consequences of employee engagement. Journal of Managerial Psychology, 21, 600-619. https://doi.org/10.1108/02683940610690169

Schaufeli, W.B., \& Bakker, A.B. (2003). Utrecht work engagement scale: Preliminary manual. Utrecht: Occupational Health Psychology Unit, Utrecht University.

Schaufeli, W.B., Salanova, M., González-Romá, V., \& Bakker, A.B. (2002). The measurement of engagement and burnout: $A$ two sample confirmatory factor analytic approach. Journal of Happiness Studies, 3, 71-92. https://doi.org/ 10.1023/A:1015630930326

Scheier, M.F., \& Carver, C.S. (1985). Optimism, coping, and health: Assessment and implications of generalized outcome expectancies. Health Psychology, 4, 219-247. https://doi.org/10.1037/0278-6133.4.3.219

Seligman, M.E., \& Csikszentmihalyi, M. (2000). Positive psychology: An introduction. American Psychologist, 55, 5-14. https://doi.org/10.1037/0003-066X.55.1.5 
Seligman, M.E., Steen, T.A., Park, N., \& Peterson, C. (2005). Positive psychology progress: Empirical validation of interventions. American Psychologist, 60, 410-421. https://doi.org/10.1037/0003-066X.60.5.410

Shimazu, A., Mastsudaira, K., Jonge, J.D., Toska, N., Watanabe, K., \& Takahashi, M. (2016). Psychological detachment from work during non-work time: Linear or curvilinear relations with mental health and work engagement? Industrial Health, 54, 282-292. https://doi.org/10.2486/indhealth.2015-0097

Shimazu, A \& Schaufeli, W.B. (2008). Work engagement: An emerging concept in occupational health psychology. BioScience, 2, 171.

Shimazu, A., Schaufeli, W., Kosugi, S., Suzuki, A., Nashiwa, H., Kato, A., et al. (2008) Work engagement in japan: Validation of the Japanese version of the Utrech work engagement scale. Applied Psychology: An International Review, 57, 510-523. https://doi.org/10.1111/j.1464-0597.2008.00333.x

Takawira, N., Coetzee, M., \& Schreuder, D. (2014). Job embeddedness, work engagement and turnover intention of staff in a higher education institution: An exploratory study. SA Journal of Human Resource Management, 12, 1-10. https:// doi.org/10.4102/sajhrm.v12i1.524

Van Berkel, J., Proper, K.I., Boot, C.R., Bongers, P.M., \& Van der Beek, A.J. (2011) Mindful 'Vitality in Practice': An intervention to improve the work engagement and energy balance among workers; the development and design of the randomised controlled trial. BMC Public Health, 11, 1-12. https://doi.org/ 10.1186/1471-2458-11-736
Vigoda-Gadot, E., \& Meiri, S. (2008). New public management values and person organization fit: A socio-psychological approach and empirical examination among public sector personnel. Public Administration, 86, 111-131. https://doi. org/10.1111/j.1467-9299.2007.00703.x

Vigoda-Gadot, E., Eldor, L., \& Schohat, L.M. (2012). Engage them to public service: Conceptualization and empirical examination of employee engagement in public administration. The American Review of Public Administration, 43, 518-538. https://doi.org/10.1177/0275074012450943

Whitney, D., \& Cooperrider, D.L. (1998). The appreciative inquiry summit: Overview and applications. Employment Relations Today, 25, 17-28.

Wirtz, N., Rigotti, T., Otto, K., \& Loeb, C. (2016). What about the leader? Crossover of emotional exhaustion and work engagement from followers to leaders. Journal of Occupational Health Psychology, 22, 86-97.

Xanthopoulou, D., Bakker, A.B., Demerouti, E., \& Schaufeli, W.B. (2007). The role of personal resources in the job demands-resources model. International Journal of Stress Management, 14, 121-141. https://doi.org/10.1037/1072-5245.14.2.121

Yeh, C.M. (2013). Tourism involvement, work engagement and job satisfaction among frontline hotel employees. Annals of Tourism Research, 42, 214-239. https://doi. org/10.1016/j.annals.2013.02.002

Youssef, C.M., \& Luthans, F. (2007). Positive organizational behavior in the workplace: The impact of hope, optimism, and resilience. Journal of Management, 33 774-800. https://doi.org/10.1177/0149206307305562 